\title{
VÍNCULOS E REDES SOCIAIS EM CONTEXTOS FAMILIARES E INSTITUCIONAIS: UMA REFLEXÃO CONCEITUAL ${ }^{1}$
}

\author{
Ana M. A. Carvalho* \\ Ana Cecília S.B. Bastos \\ Elaine P. Rabinovich" \\ Sonia M. R. Sampaio
}

\begin{abstract}
RESUMO. Propõe-se uma reflexão conceitual sobre os conceitos de vínculo e rede social. São resumidos quatro trabalhos que utilizam esses conceitos e discutidas suas convergências e divergências. Carvalho sintetiza estudos sobre vínculo na interação criança-criança. Sampaio problematiza a vinculação entre crianças de rua e educadores. Rabinovich relata observações de famílias em uma comunidade quilombola. Bastos reflete sobre redes sociais com base no discurso de mães em grupos de encontro. A comparação dessas pesquisas em termos dos conceitos de vínculo e rede social indica a conveniência de explicitação dos seus sentidos em cada caso, para permitir diálogo entre enfoques diversificados sobre as relações humanas.

Palavras-chave: vínculos, redes sociais, questões conceituais.
\end{abstract}

\section{BONDS AND SOCIAL NETWORKS IN FAMILY AND INSTITUTIONAL CONTEXTS: A CONCEPTUAL REFLECTION}

\begin{abstract}
This paper suggests a conceptual reflection on bonds and social network concepts. Four studies that use such concepts are synthesized and their convergences and divergences are discussed. Carvalho synthesizes studies on bonds in child-child interaction. Sampaio is concerned with bonds concerning homeless children and educators. Rabinovich reports observations of families in a Quilombola community. Bastos makes reflections on social network, based on the talks of some mothers during group meetings. The comparison between the studies mentioned, in terms of both concepts, that is, bonds or linkings and social network, shows the convenience of a clear explanation in relation to the meanings in each of the cases, so that the dialogue among different approaches on human relationships can be allowed.
\end{abstract}

Key words: Linking/bond, social network, conceptual questions.

\section{VÍNCULOS Y REDES SOCIALES EN CONTEXTOS FAMILIARES E INSTITUCIONALES: UNA REFLEXIÓN CONCEPTUAL}

\footnotetext{
RESUMEN. Se propone una reflexión conceptual sobre los conceptos de vínculo y red social. Son resumidos cuatro trabajos que utilizan esos conceptos y discutidas sus convergencias y divergencias. Carvalho sintetiza estudios sobre vínculo en la interacción niño-niño. Sampaio problematiza la vinculación entre "niños de la calle" y educadores. Rabinovich relata observaciones de familias en una comunidad quilombola. Bastos refleja sobre redes sociales basado en el discurso de madres en grupos de encuentro. La comparación de esas pesquisas en términos de los conceptos de vínculo y red social indica la conveniencia de explicitación de sus sentidos en cada caso, para permitir diálogo entre enfoques diversificados sobre las relaciones humanas.

Palabras-clave: vínculos, redes sociales, cuestiones conceptuales.

Apoio CNPq e FAPESP.

* Professora Titular da Universidade Católica do Salvador. Professora associada (aposentada) da Universidade de São Paulo.

\# Professora Adjunta da Universidade Federal da Bahia.

II Professora Titular da Universidade Católica do Salvador/ Faculdade de Saúde Pública da USP - CDH/ Universidade de São Paulo - LAPSI.
} 
Este texto apresenta uma reflexão conceitual e comparativa sobre os conceitos de vínculo e de rede social tal como vêm sendo utilizados em diferentes níveis e contextos de análise de processos sociais e a partir de diferentes perspectivas teóricas. Não se pretende uma revisão exaustiva desses contextos de utilização, e sim, uma exemplificação a partir da qual seja possível refletir sobre convergências e divergências identificáveis em termos de critérios de definição, amplitude dos conceitos, âmbito de aplicação, valor heurístico e outros aspectos potencialmente relevantes para a compreensão recíproca e possível complementaridade entre essas formas de utilização.

A relevância dessa reflexão situa-se, a nosso ver, no percurso atualmente bastante identificável da pesquisa e da teorização psicológicas na direção de superar o recorte clássico de seu objeto em termos de fenômenos individuais. Segundo Carvalho e Rubiano (2004), o recorte prevalente do indivíduo como foco do estudo psicológico é historicamente compreensível, uma vez que a Psicologia moderna nasceu no contexto da ascensão do individualismo burguês. Esse recorte delimitou a forma pela qual a Psicologia vem tradicionalmente lidando com conceitos como social e sociabilidade: por meio de dicotomias como individualsocial, colocando o social como externo ou até oposto ao indivíduo; ou por meio de simplificações do conceito de sociabilidade, por exemplo, identificando-a com intensidade ou freqüência de trocas sociais, ou como uma conquista da educação ou outra modalidade de "moldagem" do indivíduo - como na noção de "socialização" (conforme crítica de Richards, 1974). No entanto, desde as primeiras décadas do século 20 encontram-se discursos que questionam essas soluções e enfatizam a inseparabilidade do indivi-dual e do social - por exemplo, o de Wallon (1959/1986). Nessas concepções, o ser humano é intrinsecamente social, e se constitui como indivíduo no contexto de trocas e experiências sociais - conforme a teorização socioconstrutivista - por exemplo, Vygotsky, 1978/1984.

Como concretizar essa forma de repensar o objeto da Psicologia em termos de conceitos e de procedimentos de análise? Conceitos como interação, campo interacional e espaço interindividual já constituem esforços na direção de recortes supraindividuais - conforme, por exemplo, Carvalho, Império-Hamburger e Pedrosa, 1998; Carvalho e Rubiano, 2004. Na mesma direção situam-se os conceitos de vínculos e redes sociais, foco da reflexão deste trabalho.
Propomos dois momentos na elaboração deste texto. Em um primeiro momento, são sintetizados quatro trabalhos que utilizam esses conceitos, sendo dois em contextos institucionais e dois em contextos familiares/ comunitários. No segundo momento, recorre-se a essas descrições para desenvolver uma reflexão conceitual: $\mathrm{O}$ que é vínculo? O que é rede social? Qual a utilidade desses conceitos como instrumentos para a descrição e análise de processos sociais em suas dimensões psicológicas?

\section{EXEMPLIFICANDO FORMAS DE UTILIZAÇÃO DOS CONCEITOS}

\section{Natureza e função do vínculo entre crianças ${ }^{2}$}

Este trabalho, descrito detalhadamente em Carvalho e Rubiano (2004), relata um percurso de pesquisa sobre interação criança-criança, iniciado na década de 1979 com tentativas de descrever e analisar "estrutura de grupo" em grupos de crianças em atividade livre na escola, na creche e em outros contextos institucionais. A noção de estrutura de grupo inspirou-se originalmente na sistematização de Hinde (1979) a respeito da análise do comportamento social. Segundo Hinde (1979), essa análise requer a distinção entre pelo menos três níveis de complexidade: interações (eventos de curta duração entre dois ou mais indivíduos), relações (caracterizadas pelo padrão de interações entre determinados indivíduos no decorrer de um período de tempo) e estrutura de grupo (caracterizada pela ocorrência e padronização de relações em um grupo de indivíduos em contato estável durante um período de tempo).

Embora Hinde (1979) tenha proposto essa mesma sequiência de complexidade como percurso metodológico (partir da descrição de interações para a de relações e desta para a de estrutura de grupo), o percurso seguido no trabalho a que nos referimos aqui foi invertido. Definiu-se inicialmente uma modalidade de indicador - proximidade física entre determinados parceiros - e a partir desta descreveu-se o grupo, concebido como uma rede de relações definidas por determinado critério. Vale apontar que o conceito de rede ainda não era utilizado nesse momento, conforme por exemplo, Carvalho e Morais, 1987.

Estudos sobre a evolução da estrutura do grupo (entendida tal como descrito acima) ao longo do tempo, bem como comparações entre diferentes grupos de crianças em idade pré-escolar por meio de

2 Carvalho, A. M. A. 
critérios semelhantes, indicaram que as relações usualmente se mantinham estáveis e/ou se fortaleciam. Essas relações passaram a ser chamadas parcerias que podiam ser "privilegiadas", "preteridas" ou "neutras", segundo critérios quantitativos.

Propõe-se, neste trabalho, que a ocorrência precoce de seletividade em relação a parceiros e de atribuição diferencial de significado a parceiros diferentes expressa uma propriedade fundamental da sociabilidade humana. Seres humanos não constituem uma espécie promíscua, no sentido de que qualquer parceiro social tenha o mesmo valor efetivo. A palavra promiscuidade pode ter uma conotação negativa (talvez justamente porque contraria nossa natureza fundamental...), mas não é essa valoração que está em questão aqui. Muitas espécies animais são promíscuas no sentido de que o Outro é neutro, ou de que qualquer Outro é equivalente como parceiro (Lorenz, 1973). Sem nenhuma conotação valorativa, promiscuidade difere, qualitativa e/ou quantitativamente, de seletividade, que é a forma de sociabilidade que parece caracterizar a espécie humana.

É quando a seletividade perdura no tempo que se pode falar em relações, ou vínculos, entendidos como um padrão diferencial de interações entre parceiros em uma situação social. Ficar mais ou menos próximos, dirigir mais ou menos a atenção recíproca, estabelecer ou não trocas sociais coordenadas - são diferentes critérios pelos quais a seletividade pode se expressar em vínculos no grupo de pares de idade ou em outros contextos sociais.

Constatada a ocorrência de seletividade e vínculos no grupo de crianças, quais as questões que se colocam? Neste trabalho, perseguiu-se inicialmente a questão da função do vínculo entre pares na infância. Ao passo que, no caso do apego mãe-filho, a função do vínculo aparece como central na conceituação teórica (Bowlby, 1969), e assume a forma de hipóteses sobre seu papel na proteção contra predadores, na proximidade de modelos adultos relevantes para a aprendizagem, na transmissão cultural e outras, na literatura sobre relações entre crianças raramente foi levantada a questão funcional (Carvalho, 2002). Como primeira aproximação a essa questão, perguntou-se a crianças de 6 a 11 anos em que consiste a amizade, identificando-se a partir daí três dimensões caracterizadoras: proximidade, afinidade e cumplicidade. Atribuiu-se um sentido subjacente a essas três dimensões sob a forma do conceito de compartilhamento - respectivamente de espaços, de conhecimentos/ gostos e de atitudes/ subjetividade. Buscou-se então observar a ocorrência de compartilhamento entre díades de parceiros privilegiados e não privilegiados, e os resultados indicaram a ocorrência de diferenças significativas entre essas díades em termos de formas de comunicação: parceiros privilegiados apresentam comunicação mais abreviada, indicando compartilhamento anterior de significados e maior potencialidade de criação de novos significados na situação interacional (Carvalho e Rubiano, 2004).

Sugere-se, a partir disso, que o compartilhamento é maximizado pela existência do vínculo, e que este é, simultaneamente, fortalecido pelo compartilhamento, em uma relação construtiva dialética. Compartilhamento do quê? Daquilo que é construído na própria interação social: atribuição de sentido a objetos, a palavras e outros códigos, saberes e competências - a essência da vida sociocultural. $\mathrm{O}$ vínculo, persistente no tempo, favorece a continuidade dessas coisas socialmente construídas, que por sua vez favorecem o fortalecimento dos vínculos e possivelmente seu desdobramento em outras relações.

Neste contexto entra a idéia de redes sociais ou redes de vínculos. Em um grupo de crianças, raramente as relações podem ser isoladas: elas se desdobram em tríades, em grupos de quatro ou cinco. O conceito original de estrutura de grupo pode, deste ponto de vista, ser ampliado para uma concepção de subgrupos como malhas ou nós de uma rede dinâmica de relações sociais (vínculos - sejam estes positivos ou negativos, relações de aproximação ou de evitação), na qual cada indivíduo se situa e da qual faz parte. É nesse tecido social concreto que o conhecimento, a identidade e o pertencimento cultural se efetivam.

\section{Vínculos entre crianças com experiência de rua e educadores $^{3}$}

O objetivo deste trabalho foi problematizar o estabelecimento de vínculos entre crianças com experiências de rua e seus educadores, no contexto de atendimento dessas crianças por uma organização governamental responsável pela implementação de políticas públicas em Salvador, BA. A análise baseouse em reuniões gravadas com os educadores no decorrer de um processo de pesquisa-ação-formação.

É importante esclarecer qual o uso do conceito de "vínculo" nesse trabalho. Pensando nesse conceito como tributário de "seletividade" e "durabilidade", seria difícil falar de vínculo entre o educador social e sua clientela. Nem o educador nem a criança em questão têm a prerrogativa da escolha dentro de um

\footnotetext{
Sampaio, S. M. R.
} 
universo de possibilidades relacionais: a criança é encaminhada para ser atendida por um educador que, naquele dia, está de plantão e, caso a criança retorne, encontrará esse mesmo educador no máximo duas vezes na mesma semana. Considerando a outra dimensão que implica em tempo transcorrido, o conceito é igualmente difícil de ser considerado: inicialmente, porque, se tudo correr como orienta a legislação, a situação da criança no acolhimento é necessariamente provisória, não devendo ultrapassar 90 dias.

Não obstante, tanto a literatura específica quanto os depoimentos dos educadores referem-se à centralidade do "vínculo" nessa relação como condição para que o trabalho educativo possa se dar. Cyrulnik (2005), referindo-se a crianças que perderam suas referências afetivas de forma definitiva, diz que elas, tendo perdido "a estrela-guia", precisarão investir no resto da constelação. No caso desses meninos e meninas, o "resto da constelação" pode ser um adulto disponível, num espaço institucional que, na grande maioria das vezes, é significado de escuta e disponibilidade para acolher uma gama variada de demandas que podem, inclusive, adquirir as cores do conflito. Mas a criança sabe que esse adulto está lá por ela, sendo ela a razão de existir desse profissional. Talvez, ao invés de falar em "vínculo" pudéssemos ser mais fiéis à situação observada falando em uma relação de "suporte", que contempla a provisoriedade e a ausência de escolha dos parceiros, mas permite, ao mesmo tempo, que a criança estabeleça, com o adulto, laços de confiança.

Inicialmente, perguntou-se de que depende o estabelecimento de uma relação nesse contexto. Foram identificadas as seguintes pistas: (1) da compreensão do educador sobre o fato de que as crianças precisam da rua para sobreviver, e de sua consideração efetiva da criança como co-autora de sua realidade; (2) da compreensão do educador sobre sua missão: controlar ou emancipar?; (3) do compartilhamento de objetivos entre a instituição e o educador; (4) da possibilidade do educador de oferecer escuta e apoio à criança; (5) de sua capacidade de narrar e de provocar narrativas. Além desses aspectos relacionados ao educador, foram identificadas, como condições para o estabelecimento do vínculo, agora do ponto de vista da criança: (1) experiências anteriores de vinculação; (2) sentimentos da criança diante de um adulto (estranho) e de um ambiente fechado (a criança deseja vinculação? Está abandonada? É mais ou menos refratária à intervenção de um adulto?).

Além das dificuldades colocadas pela provisoriedade e pela ausência de seletividade, a duração da permanência da criança na rua também se relaciona à dificuldade de estabelecimento de vínculos - quanto mais longa a permanência na rua, maior a dificuldade de vinculação. Além disso, há aspectos ligados às condições de atendimento: há mais educadores homens do que mulheres, resultando em ambigüidade de relações (sedução que ronda o trabalho pedagógico); há poucas opções de encaminhamento para as crianças a partir da situação de atendimento; e os educadores carecem de uma formação continuada.

Por outro lado, algumas condições são favorecedoras: a compreensão do trabalho como ação política; a atuação compartilhada com outros educadores; a percepção, pelas crianças, de que os educadores fazem parte de um equipamento protetor que difere, por exemplo, da polícia; e, especialmente, a identificação dos educadores com as crianças, resultante do fato de partilharem histórias e vivências tidas como marginais, dificuldades na escola, pobreza e moradia em bairros periféricos. Essa identificação entre as histórias de vida dos educadores e das crianças que atendem parece ser um importante aspecto a considerar quando discutimos a dedicação desses profissionais ao trabalho que realizam, o qual é considerado unanimemente como "muito difícil".

Mais um aspecto a considerar refere-se às repercussões, na subjetividade do educador, do encontro com uma alteridade radical. Crianças sem família experimentam dificuldade em estruturar o tempo de suas histórias; organizam pouco o sentimento de passagem de tempo em seu mundo sem estabilidade; distantes de suas origens, não têm histórias a contar sobre si mesmas, precisando fabricá-las; são mais competentes na expressão e leitura corporais do que com as palavras; prezam pouco a própria vida, ou porque se pensam imortais ou porque sabem que seu eventual desaparecimento não causa perturbação; essa incompreensão do futuro dificulta a tarefa pedagógica, que implica fazer planos, ter projetos. Assim, ao mesmo tempo em que se identificam com as crianças, devem aprender a lidar com esse "outro" - cuja diferença menos importante é a idade, já que uma criança com experiência de rua apaga de forma significativa a fronteira entre "mundo adulto" e "mundo infantil": ela sobrevive sem a proteção de uma família, não se encontra no espaço culturalmente dedicado às crianças - a escola -, conhece e/ou usa drogas e tem antecipadas experiências sexuais, uma das prerrogativas do ser "adulto" no imaginário social.

Nesse confronto, o educador se protege com uma distância "ótima" que permita preservar sua 
integridade psicológica. Não se sente preparado para a imprevisibilidade, percebe que sua ação é pouco visível e até recusada pela sociedade; sente-se "enxugando gelo". Segundo o depoimento de um dos educadores, "o menino tá segurando o educador (...) dando a mão para ele se equilibrar": a lógica se inverte...

\section{Família e comunidade ${ }^{4}$}

Este estudo objetiva contribuir para a discussão de vínculos e redes sociais, apontando que $o$ compartilhamento atua como reforçador de vínculos ao mesmo tempo que os constitui, tanto espacial quanto temporalmente, condensando-os em um "espaçotempo". O termo comunidade, portanto, está referido a uma esfera comum de convivialidade.

O estudo baseou-se na análise de três famílias de uma localidade - o Carmo - reconhecida como remanescente de quilombo. As famílias foram analisadas por meio de vários instrumentos: anamnese da família e da criança; fotos e desenhos da moradia; entrevistas com coordenadores da escola e creche e com funcionários do Posto de Saúde; informações de fontes fortuitas.

O Carmo é uma área rural, localizada a $25 \mathrm{~km}$ do centro de São Roque, município paulista ao qual pertence. Vem perdendo a sua vocação rural e seu potencial de gerar empregos nessa área para tornar-se um apêndice urbano (Rabinovich, 2002; Rabinovich \& Gallo, 2005). Os moradores, de lavradores e agricultores tornaram-se jardineiros e pedreiros; as mulheres, que trabalhavam na roça, tornaram-se domésticas e donas de casa. Não obstante, a localidade continua a exibir aspecto rural, sem comércio, serviços, diversões; é um vilarejo, conectado à cidade por ônibus, e os empregos são oferecidos por um loteamento elegante localizado nas proximidades.

Dos três casos estudados, uma mulher era faxineira na pré-escola; outra trabalhava como costureira e a terceira era dona de casa. Os homens eram pedreiros e jardineiros.

A primeira mulher morava em uma casa conjugada à de sua mãe, ambas descendentes dos moradores originais do Carmo. Um dos filhos morava com a avó, e o outro, de 6 anos, dormia no quarto com a mãe, que havia perdido o companheiro recentemente. A filha recebia bolsa-escola e ela, renda-cidadã. Dois meninos estudavam e trabalhavam como jardineiros. Dois fatos podem ser ressaltados na análise desta moradia: a presença de livros na estante que substituía o altar encontrado em outros casos; e um quarto de adolescente com bichos de pelúcia, fotos de cantores e

4 Rabinovich, E. P. atores, objetos de toucador, perfume, creme etc. A presença de livros sugere que a frequiência à escola, mesmo na condição de faxineira, de algum modo aproximou a mãe de um saber escrito, geralmente ausente das moradias populares - exceto a bíblia, presente nas moradias de evangélicos. O quarto da adolescente remeteu ao único quarto semelhante, visto em Areia Branca, Lauro de Freitas, Bahia (Rabinovich, 2002). Essas meninas-moças puderam projetar em seu ambiente externo algo de seu ambiente interno, mostrando um tipo de subjetivação que ao mesmo tempo as aproxima e as afasta de meninas-moças da cidade: aproxima-as porque alimenta desejos e fantasias amorosas associados a ídolos da mídia e objetos de sedução; afasta-as porque umas estão na sociedade de consumo e outras não, pertencendo a um ambiente em que os valores estão nas pessoas, e não apenas nas coisas. Essas duas adolescentes "compartilham", ao lado de suas vidas comunitárias, uma comunidade propiciada pela mídia que captura o imaginário e possibilita expressar desejos. Essa expressão, por sua vez, é fundante de seu próprio desenvolvimento, pois demarca territórios onde o seu "eu" se manifesta.

Na segunda família estudada no Carmo, a mulher trabalhava em uma ONG localizada no bairro, tendo um emprego estável, ao contrário do marido, pedreiro eventual. A esposa, descrita como autoritária e rígida, indispôs-se com a família do marido e com líderes da ONG, vindo a trocar de emprego, indo trabalhar longe. O pai e, principalmente, a filha mais velha, encarregam-se dos demais três filhos. Sobre essa família obtiveram-se opiniões divergentes: uns a denominavam "família-modelo", por sua visão progressista quanto à educação dos filhos; outros achavam que a mãe causava problemas aos filhos, devido à sua ambição desmedida, à não-aceitação de pertencer ao local e ao fato de trabalhar. A análise da moradia confirmou ambas as opiniões: a casa, construída inicialmente pelo Projeto Mutirão coordenado pela ONG, ergue-se qual um castelo no meio das demais. Todo esforço dos pais está sendo colocado na casa. Deduz-se que as crianças estão sendo criadas a reboque, e não na frente das necessidades do casal. Embora a casa disponha de dois quartos, dormem todos em uma cama; uma escada em caracol une os dois andares, representando evidente perigo de acidentes para crianças, como já ocorreu. A menina mais velha não pode freqüentar atividades de que gosta, para ficar cuidando dos irmãos. A estante da sala perdeu a característica de altar sagrado, sendo apenas um altar profano, onde 
estão os ídolos TV e som, de tamanho desnecessariamente grande para o uso real, porém necessário para indicar o seu valor: um valor que os sobrepõe aos quadros de santos, dispostos como santos dessacralizados, apenas como quadros. A deidade família está representada apenas por um retrato de criança. Assim, os valores maternos progressistas e urbanóides estão bem representados na moradia, em contradição com um modo de educar que segue padrões "rurais" e tradicionais. Embora imersa em uma rede sociofamiliar extensa e coletivista, a atitude da mãe fechou a casa e a família em um casulo. Está ocorrendo uma rede familiar-privatizada, enfraquecendo os possíveis vínculos com a comunidade mais ampla.

A terceira casa está em um terreno familiar cedido por um parente. Foi construída por mutirão, posteriormente abandonado; a casa tem apenas telhado e paredes. Dentro, poucos móveis além das camas, em desordem e sujeira. O banheiro e o tanque de lavar roupa são divididos com a mãe do pai, vizinha, o que gera conflitos. É uma das famílias mais desfavorecidas do local. Os irmãos do pai não se casaram, vivendo com a avó na casa vizinha. A avó a todos domina. A mãe, muito agarrada aos filhos, impede que se movimentem pelo local, sem colocar limites ao que fazem em casa. A avó recrimina a mãe pelo seu sistema educativo e desvaloriza a nora, que se apega às crianças, que por sua vez convivem com essa duplicidade. Em um encontro com o pai, este se revelou articulado, com um discurso politizado em busca de direitos, algo inusual no local. Vínculos possantes unem os familiares, positiva e negativamente, criando uma ambivalência vincular e um desejo, por parte do pai, de se apropriar do destino de sua comunidade: o de ser um quilombo. A rede social mais ampla, assim, aparece como compensatória ante as dificuldades internas; aceitar a origem quilombola é um elemento de força vincular inquestionável, que pode dar o sentido de permanência no local e da própria existência do local (conforme conceito de enraizamento de Weil, 1949/2001).

Este estudo aponta dois elementos intrínsecos à questão do vínculo e da rede social: um elemento sincrônico e um diacrônico, ambos atuando de modo a propiciar significados compartilhados. $\mathrm{O}$ primeiro se relaciona à vida cotidiana, familiar e grupal e cria compartilhamento pelo exercício de práticas cotidianas. $\mathrm{O}$ segundo se liga à história familiar e grupal; o compartilhamento decorre de propiciar uma comunidade de destino que une passado e futuro e, ao orientar o sentido das vidas, as irmana. Sentido e significado adquirem a sua plena acepção, quer como sinônimos quer como complementaridade. Ao fazerem convergir os olhares, seja devido a uma vivência cotidiana, seja a uma origem que orienta os caminhos para uma certa direção, estruturam e mantêm vínculos, atribuindo-lhes valências positivas ou negativas.

\section{Família e redes sociais 5}

Neste trabalho a família é tomada como unidade de análise e parte-se da hipótese de que é o observatório privilegiado do vínculo social em seus redutos privados (Cicchelli-Pugeault \& Cicchelli, 1998). A família pode ser pensada como "rede": uma metáfora correspondente a uma descrição de nossa sociedade como uma sociedade de tipo relacional, interdependente, inscrita numa identidade brasileira enraizada em importantes componentes afrodes-cendentes e indígenas (Rabinovich, 2003). Sarti (2004) afirma que a família pobre não se constitui como um núcleo, mas como uma rede com ramificações que envolvem uma rede de parentesco como um todo, configurando uma rede de obrigações morais que enreda os indivíduos em dois sentidos: ao dificultar sua individualização e ao viabilizar sua existência dando-lhes apoio e sustentação básicos, solucionando problemas do cotidiano e possibilitando o sistema de trocas necessário à manutenção dos vínculos sociais e da comunicação (Petrini, 2005; Valverde, 2003).

$\mathrm{O}$ estudo analisou material recolhido no projeto "Conversas de Família", no qual mães (e às vezes pais) se reuniam com pesquisadores participantes de um projeto social dirigido à comunidade de Novos Alagados, BA. A partir da transcrição das reuniões, foram elaboradas categorias temáticas, de posicionamento e interativas (Bastos, 2005). As primeiras focalizavam o conteúdo das falas: preocupações, valores, práticas e objetivos ligados à criação de filhos, seus circunscritores, significados de mater-nidade e paternidade. As segundas baseavam-se no protagonismo do sujeito, tanto em relação ao narrado quanto no próprio processo do grupo ao longo das sessões. Nesse sentido, o grupo é tomado como um microcosmo da relação projeto social-família, objetivo último do trabalho em que este projeto se insere. No caso de categorias interativas, a ênfase é inteiramente no grupo: referem-se a trocas interativas entre os participantes do grupo ou entre participantes e pesquisadores, com ênfase no processo do grupo; descrevem as conversações, mecanismos, aconselhamentos e formação de vínculos ocorridas ao longo desse processo.

\footnotetext{
Bastos, A. C. S.
} 
Em um primeiro nível de análise, referente às categorias temáticas, foram focalizadas as redes sociais na descrição de práticas educativas. Tais redes envolvem a família (mãe, pai, avós, irmãos, vizinhos); sua atuação pode ser referida como positiva ou negativa; problemas que dificultam a criação de filhos, na percepção dos pais, como ausência de um dos pais, problemas conjugais, interferência de outros membros da família e de vizinhos. As redes têm uma dinâmica própria: constituem-se, modificam-se, dissolvem-se; comportam relações simétricas, assimétricas, suportivas, conflitivas, estáveis ou instáveis. Em um segundo nível, o de categorias de posicionamento, identificaram-se relações ou tentativas de estabelecimento de relações fora daquele primeiro âmbito familiar, no âmbito do próprio grupo ou de outras instituições: busca de explicação para problemas de comportamento, expectativa de ajuda do psicólogo, validação do próprio grupo "Conversa de Família", referências à obtenção de ajuda ou apoio no âmbito da rede social constituída por projetos sociais e instituições e ao trabalho desenvolvido no Centro Educativo, expressão de identidade social a partir do próprio lugar na família, papel na comunidade, espaço profissional etc. Finalmente, quanto às categorias interativas, evidenciaram: compartilhamento de saberes sobre criação de filhos, sugestão de modos de obter ajuda no âmbito da rede social formal, discordâncias ou inovações quanto aos conteúdos discutidos no grupo, avaliação de ganhos no grupo em termos de competências e sua aplicação no contexto familiar, reflexões a partir de falas de outros participantes, partilha de estados afetivos e posicionamento quanto a opiniões ou estados afetivos relacionados à participação no grupo.

Concluindo, o estudo argumenta que a experiência do grupo "Conversa de Família" pode ser analisada como um microcosmo da relação (vínculo) entre a comunidade e o projeto social. A conversação em grupo revelou-se como uma situação em aberto que favorece a emergência de novidade psicológica.

\section{RETOMANDO OS CONCEITOS DE VÍNCULO E DE REDES SOCIAIS}

Certas palavras ou expressões caem às vezes no agrado de meios científicos ou acadêmicos, e passam a ser utilizadas de forma relativamente livre, sem referenciamento recíproco, com o risco de esvaziar-se de sua utilidade conceitual. É no sentido de minimizar esse risco no caso da utilização dos conceitos de vínculo e de redes sociais na Psicologia que propomos esta reflexão, visando esclarecer, comparar, diferenciar
- se for o caso - formas de sua utilização a partir dos trabalhos descritos acima.

Em que dimensões essa utilização pode ser comparada? Um ponto de partida pode ser o das conceituações de vínculo e redes nos trabalhos aqui descritos. Outros recortes potencialmente úteis parecem ser o recorte "contextos familiares e institucionais" e as relações entre níveis de análise de processos sociais, segundo a proposta de Hinde (1987): nível de interações e relações interpessoais, relações mediadas por papéis, relações entre indivíduos e contextos institucionais, historicamente situados.

Os dois primeiros trabalhos foram tomados aqui como exemplos de contextos institucionais (a creche ou grupo de brinquedo, em um caso; uma organização governamental no segundo) por não focalizarem especificamente a família. Apesar desse rótulo aparentemente homogeneizador, trata-se de contextos completamente diversos do ponto de vista das relações e redes sociais implicadas, o que se reflete na forma de utilização desses conceitos em cada caso. Carvalho propõe, como conceituação de vínculo para fins de sua análise, um padrão diferencial de interações entre parceiros em uma situação social, expressando seletividade em relação a certos parceiros ao longo de um período de tempo. Essa conceituação implica duas dimensões que são retomadas por Sampaio, ao problematizar o estabelecimento de vínculos entre crianças de rua e seus educadores: seletividade $e$ durabilidade. Sampaio coloca em questão a adequação do conceito de vínculo para uma situação em que, aparentemente, nenhuma dessas duas dimensões está presente, pelo menos no nível de relações interpessoais, já que não há constância nem permanência no tempo de determinados indivíduos em interação - em contraste com a situação descrita por Carvalho. A literatura da área, no entanto, insiste na importância da vinculação para a viabilização do trabalho educacional com crianças de rua. Qual é o sentido de vínculo nesses dois casos? Serão as dimensões de seletividade e durabilidade essenciais para a conceituação de vínculos? em que sentido, e definidas por quais parâmetros?

Tome-se um caso clássico de vínculo, consagrado na literatura psicológica especialmente a partir da obra de Bowlby (1969): O apego mãe-filho. O sentido de seletividade, nesse caso, é evidentemente diferente do que ocorre no caso de relações de amizade e outras relações ao longo da vida: não se refere a uma escolha de parceiros individuais (a mãe não escolhe o filho, nem este escolhe a mãe), e sim ao fato de que, dadas as condições propícias de interação e convivência, o 
apego cria seletividade ao longo de um certo período de tempo (tipicamente, os primeiros sete ou oito meses de vida), com um ou mais parceiros. Dizer que o apego cria seletividade não implica uma relação linear: o processo de constituição do apego é, ao mesmo tempo, um processo de constituição de seletividade, e a seletividade fortalece o próprio apego $-\mathrm{e}$, nesse sentido, a noção de seletividade aqui se aproxima novamente do que ocorre na constituição de vínculos entre pares, descrita por Carvalho, embora a seqüência dinâmica de seletividade e vinculação possa, talvez, estar alterada neste caso: o que vem primeiro, aqui, parece ser a atração por um parceiro (seletividade inicial), que propicia a construção de compartilhamentos, e com isso, por sua vez, aumenta a seletividade e força do vínculo.

Quanto à durabilidade, como se comparam o vínculo mãe-filho e os vínculos entre crianças descritos por Carvalho? Essa comparação deixa claro que a noção de durabilidade precisa ser flexível. Em princípio, o vínculo mãe-filho se estende por toda a vida dos parceiros, ou por uma boa parte dela. No caso de crianças que brincam juntas, sua duração parece ser delimitada por fatores circunstanciais e também pela idade das crianças: para crianças mais jovens, o vínculo persiste enquanto há convivência freqüente ("eu tinha um amigo, ele mudou de escola"); pode durar alguns dias, alguns meses, ou, se houver oportunidade de convivência e construção de afinidades e de cumplicidade, pode, em alguns casos, se estender até à vida adulta (Carvalho \& Rubiano, 2004). O critério estabelecido por Carvalho, de falar em vínculo quando a seletividade perdura ao longo do tempo, é basicamente um critério operacional: em seu contexto de pesquisa, a seletividade é, ela própria, definida pela persistência no tempo (desde alguns dias até um ou mais semestres de convivência), já que não há outros acessos metodológicos para identificá-la com os procedimentos de observação adotados. Quer seja medida por proximidade, quer por natureza e qualidade das interações, a identificação da seletividade requer, em princípio, um espaço de tempo de observação. No entanto, essa não é uma exigência lógica: poder-se-ia falar em seletividade ao longo de uma única sessão de observação, se a quantidade e qualidade de dados disponíveis permitissem a diferenciação de parceiros em termos de seletividade unilateral ou recíproca. Arriscando uma analogia baseada na literatura em sentido lato, podem-se reconhecer paixões fulminantes que duram apenas dias ou semanas.

Vistos deste ângulo, os vínculos mãe-filho e criança-criança diferem nas duas dimensões, ficando mais saliente a dimensão durabilidade no primeiro caso, e a dimensão seletividade no segundo. Por outro lado, aproximam-se, por se tratar, em ambos os casos, de vínculos interindividuais ou interpessoais. Esta dimensão talvez seja útil para explorar semelhanças e diferenças no caso dos demais trabalhos descritos aqui.

Sampaio indica uma pista para outra leitura possível de vinculação: o adulto não é necessariamente o mesmo em cada encontro, mas a criança sabe que é "um adulto disponível, num espaço institucional que (...) é significado de escuta e disponibilidade...”; “... a criança sabe que esse adulto está lá por ela, sendo a razão de existir desse profissional". É possível pensar, neste caso, que, à quantidade e/ou qualidade das interações vividas, condição para o desenvolvimento de vínculos nas relações interpessoais, acrescenta-se outra dimensão: a dos papéis. O adulto educador talvez não compareça a esta situação interacional como um indivíduo, mas sim, como representante de um tipo de relação possível: uma relação de confiança e suporte, que, evidentemente, tem que ser mediada por interações concretas com alguns outros com certas características, como sugerem os facilitadores de relacionamento identificados no estudo (compreensão, oferecimento de escuta e apoio, capacidade de narrar e provocar narrativas), mas que parece poder se generalizar para outros outros, na medida em que estes outros partilhem as mesmas concepções e atitudes em relação a essa criança. Como aponta Sampaio, essa possibilidade de vinculação não escapa de uma série de dificuldades, atribuídas, entre outras causas, à falta de formação continuada dos educadores, que dificulta essa partilha, e ao estranhamento de alteridades diferentes. Tanto a necessidade de formação específica quanto esse estranhamento sugerem que, do ponto de vista biológico - e diferentemente do vínculo mãe-filho ou do vínculo entre pares - esse tipo de vínculo tem poucos mecanismos facilitadores em termos de préadaptações: talvez apenas, e basicamente, a empatia; talvez outros, entre os quais, como aponta Sampaio, o compartilhamento de histórias e vivências, gerando algum nível de identificação.

Introduzir a noção de papéis abre espaço para o reconhecimento da complexidade de níveis de análise do comportamento e da vida social. Para além de relações interpessoais, ou mesmo de relações mediadas apenas por papéis, podemos pensar em vínculos institucionais, históricos, políticos, culturais, provavelmente mediados por outros mecanismos e processos além daqueles que regulam relações interpessoais. 
Rabinovich aponta que, na comunidade descrita, "a origem quilombola é um elemento de força vincular inquestionável"; indica, ainda, um elemento sincrônico (a vida cotidiana, referindo-se à convivência concreta da família e do grupo) e um elemento diacrônico (a maneira pela qual essa vida se liga à história familiar e grupal) como intrínsecos à questão do vínculo e da rede social. Em cada uma das famílias analisadas, encontram-se resultados diversos do jogo entre os fatores e processos que conduzem à vinculação e à constituição e fortalecimento ou não de redes sociais intrafamiliares e no âmbito da comunidade analisada. É interessante notar, também, nesta análise, a presença recorrente do conceito de compartilhamento e de seu papel como reforçador e ao mesmo tempo constituinte de vínculos.

No trabalho de Rabinovich e, especialmente, no trabalho de Bastos, o conceito de rede social comparece de forma mais recorrente do que nos dois trabalhos anteriores. Este fato é especialmente interessante, considerando-se que estes dois últimos trabalhos foram tomados como exemplos de contextos familiares. É fácil notar, no entanto, que essa distinção é ambígua: por focalizarem a família situada em contextos comunitários e em projetos sociais, estas análises não podem escapar das dimensões institucionais, culturais e históricas. Mais uma vez, podemos notar que a dicotomia institucional-familiar, adotada para fins descritivos neste trabalho, referindo-se basicamente a situações e focos de observação, não se sustenta em termos conceituais.

A presença mais forte do conceito de rede nestes dois casos sugere uma questão para reflexão futura: será esse conceito mais útil ou necessário quando as dimensões de análise se distanciam do nível microssocial (interações concretas) na direção do nível macrossocial? Pensamos que, novamente, esta resposta depende da conceituação e do tratamento dado ao conceito de rede social em cada nível. Assim, por exemplo, enquanto em Carvalho o conceito é delimitado sob a forma de rede de vínculos interpessoais, em Rabinovich e em Bastos adquire outras dimensões possíveis - por exemplo, pertencimento à comunidade, rede sociofamiliar extensa versus privatizada, rede de parentesco, rede de obrigações morais, rede social constituída por projetos sociais e instituições. A explicitação dessas dimensões é, parece-nos, um requisito desejável para que a utilização desse conceito possa ser compartilhada de maneira produtiva em diferentes níveis de análise.

Da mesma forma, parece-nos que a noção de vínculo requer mais trabalho conceitual. As dimensões de seletividade e durabilidade, apontadas acima, parecem insuficientes para caracterizar a natureza do vínculo enquanto fenômeno que se manifesta em contextos sociopsicológicos diferenciados, portanto, também para permitir uma discussão sobre a adequação de sua utilização nesses contextos. Talvez seja necessário, como sugere Hinde (1979), qualificar as relações por meio de critérios mais explícitos para avaliar quais delas se candidatam ao rótulo de vínculos, e de que forma entram na composição de redes sociais e são constituídas por elas.

Finalmente, sugerimos que também o conceito de compartilhamento (ou partilha) merece uma análise conceitual e metodológica mais cuidadosa, que não cabe empreender aqui, mas que fica como sugestão para futura reflexão.

\section{REFERÊNCIAS}

Bastos, A. C. S. (2005). Contextos e trajetórias de desenvolvimento: a situação de famílias participantes e não participantes de projetos sociais. (Relatório de pesquisa). Brasília: CNPQ.

Bastos, A.C. (2005). "Conversas de família": significado e configuração de padrões relacionais no contexto de um projeto social, em um bairro do subúrbio ferroviário de SalvadorBahia. Anais do IV Congresso Norte-Nordeste de Psicologia, Salvador. (CD-ROM).

Bowlby, J. (1969). Attachment and Loss (Vol. 1). Attachment. London: Hogarth.

Carvalho, A. M. A. (2002). Seletividade e vínculo na interação entre crianças. Tese de Livre-Docência Não-Publicada, Instituto de Psicologia da Universidade de São Paulo.

Carvalho, A. M. A. (2005). Vínculos e redes sociais de crianças em grupos de brinquedo. Anais do IV Congresso NorteNordeste de Psicologia. Salvador. (CD-ROM).

Carvalho, A. M. A., Império-Hamburger, A. \& Pedrosa, M. I. (1998). Interaction, regulation and correlation: Conceptual discussion and empirical examples in the context of human development. In M. Lyra \& J. Valsiner (Eds.), Construction of psychological processes in interpersonnal communication (pp. 155-180). Stamford, Connecticut: Ablex.

Carvalho, A. M. A. \& Morais, M. L. S. (1987). A descrição do comportamento social da criança: uma contribuição. Psicologia, 13(1), 37-54.

Carvalho, A. M. A. \& Rubiano, M. R. B. (2004). Vínculo e compartilhamento na brincadeira de crianças. Em M. C. Rossetti-Ferreira, K. S. Amorim, A. P. S. Silva \& Ana M. A. Carvalho (Orgs.) Rede de significações: uma perspectiva para $o$ estudo do desenvolvimento humano (pp. 171-187). Porto Alegre: ArtMed.

Cicchelli-Pugeault \& Cicchelli (1998). Las teorías sociológicas de la família. Buenos Aires: Nueva Visión.

Cyrulnik, B. (2005). O murmúrio dos fantasmas. São Paulo: Martins Fontes.

Hinde, R. A. (1979). Towards understanding relationships. Londres: Academic. 
Lorenz, K. (1973). A agressão: uma história natural do mal. São Paulo: Martins Fontes.

Petrini, J. C. (2005). A família e as políticas familiares [Resumo]. Em IV Congresso Norte-Nordeste de Psicologia. Anais (CDROM). Salvador.

Rabinovich, E. P. (2002). Contextos coletivistas de desenvolvimento: uma análise comparativa intracultural. Em E. R. Lordelo, A. M. A. Carvalho \& S. H. Koller (Orgs.), Infância brasileira e contextos de desenvolvimento (pp. 165204). São Paulo/ Salvador: Casa do Psicólogo / EDUFBA.

Rabinovich, E. P. \& Gallo, P. R. (2005). Estudo das famílias de uma comunidade quilombola do Carmo (São Roque, SP). Em J. C. Petrini \& V.R.S. Cavalcanti (Orgs.), Família, sociedade e subjetividades: uma perspectiva interdisciplinar (pp. 195209). Petrópolis: Vozes.

Rabinovich, E. P. Análise do Carmo em sua relação com os projetos sociais [Resumo]. Em IV Congresso Norte-Nordeste de Psicologia. Anais (CD-ROM), Salvador.

Richards, M. P. M. (1974). The integration of a child into a social world. Cambridge: Cambridge University.

Sampaio, S. R. Sampaio, S.M.R. (2005). A construção do vínculo entre crianças de rua e o educador social [Resumo]. Em IV
Congresso Norte-Nordeste de Psicologia. Anais (CD-ROM). Salvador.

Sarti, C. A. (2004). Algumas questões sobre a família e políticas sociais. Em C. Jacquet \& L. F. Costa (Orgs.), Família em mudança (pp. 193-204). São Paulo: Companhia Ilimitada.

Valverde, M. (2003). A transformação mediática dos modos de significação. Disponível em <http://www.facom.ufba.be/ Pos/monclar>. (Acesso em: 10/08/03 ).

Vygotsky, L. (1978/1984). A formação social da mente. São Paulo: Martins Fontes.

Wallon, H. (1959/1986). O papel do outro na consciência do eu. Em M. J. G. Werebe \& J. Nadel-Bruffert (Orgs.). Henri Wallon (pp. 158-167). São Paulo: Ática.

Weil, S. (1949/2001). O enraizamento. Bauru: EDUSC.

Recebido em 28/09/2005 Aceito em 14/06/2006

Endereço para correspondência: Ana M. A. Carvalho. Rua da Paz, 25, Itapoá, CEP 41610-330, Salvador-BA, Brasil. E-mail: amacarva@uol.com.br 